\title{
Vapor-Based Initiator Coatings for Atom Transfer Radical Polymerization**
}

\author{
By Xuwei Jiang, Hsien-Yeh Chen, Gemma Galvan, Mutsumi Yoshida, and Joerg Lahann*
}

A novel polymeric initiator coating for surface modification via atom transfer radical polymerization (ATRP) is reported. The synthetic approach involves the chemical vapor deposition of [2.2]paracyclophane-4-methyl 2-bromoisobutyrate and can be applied to a heterogeneous group of substrates including stainless steel, glass, silicon, poly(dimethylsiloxane), poly(methyl methacrylate), poly(tetrafluoroethylene), and polystyrene. Surface analysis using X-ray photoelectron spectroscopy and Fouriertransformed infrared spectroscopy confirmed the chemical structure of the reactive initiator coatings to be consistent with poly[( $p$-xylylene-4-methyl-2-bromoisobutyrate)-co-( $p$-xylylene $)]$. Appropriate reactivity of the bromoisobutyrate side groups was confirmed by surface initiated atom transfer radical polymerization of a oligo(ethylene glycol) methyl ether methacrylate. After solventless deposition of the CVD-based initiator coating, hydrogel films as thick as $300 \mathrm{~nm}$ could be conveniently prepared within a $24 \mathrm{~h}$ timeframe via ATRP. Moreover, the polymerization showed ATRP-specific reaction kinetics and catalyst concentration dependencies. In addition, spatially controlled deposition of the initiator coatings using vapor-assisted microstructuring in replica structures resulted in fabrication of spatially confined hydrogel microstructures. Both protein adsorption and cell adhesion was significantly inhibited on areas that were modified by surface-initiated ATRP, when compared with unmodified PMMA substrates. The herein described initiator coatings provide a convenient access route to controlled radical polymerization on a wide range of different materials. While demonstrated only for a representative group of substrate materials including polymers, metals, and semiconductors, this method can be expected to be generically applicable - thereby eliminating the need for cumbersome modification protocols, which so far had to be established for each substrate material independently.

\section{Introduction}

Defined and stable surface properties are essential characteristics of many future biodevices, such as high-density protein and DNA arrays, ${ }^{[1,2]}$ micro total analysis systems ( $\mu$ TAS) ${ }^{[3]}$ microfabricated cell sorting and detection devices, ${ }^{[4]}$ or miniaturized networks for cell isolation and culturing. ${ }^{[5,6]}$ Because of the high surface-to-volume ratios typically encountered in miniaturized biodevices, even minor variations in the surface chemistry can reduce device performance. ${ }^{[7]}$ As a consequence,

[*] Prof. J. Lahann, Dr. X. Jiang, H. Y. Chen, G. Galvan, Dr. M. Yoshida Department of Chemical Engineering, University of Michigan Ann Arbor, MI 48109 (USA)

E-mail: lahann@umich.edu

Prof. J. Lahann

Department of Chemical Engineering, Materials Science and Engineering, University of Michigan

Ann Arbor, MI 48109 (USA)

Prof. J. Lahann

Department of Macromolecular Science and Engineering, University of Michigan

Ann Arbor, MI 48109 (USA)

[**] X. J. and H. Y. C. contributed equally to this work. The authors gratefully acknowledge support from the NSF in form of a CAREER grant (DMR-0449462) and funding from the NSF under MRI program (DMR 0420785). We thank Professor Ronald G. Larson, University of Michigan, for use of the fluorescence microscope. development of well-defined biointerfaces, which combine the biological functionality of naturally derived support matrices with the versatility and robustness of synthetic polymers will be increasingly important for a large number of biotechnological applications. Towards this end, surface initiated controlled radical polymerizations, ${ }^{[8]}$ such as reversible addition-fragmentation chain transfer (RAFT) polymerization, nitroxide-mediated polymerization (NMP), and atom transfer radical polymerization (ATRP), have recently attracted increasing interest. Among the different controlled radical polymerization methods, surface-initiated ATRP has been used most widely because of its tolerance to water and impurities, compatibility with a wide range of different functional monomers, and the relatively low polymerization temperatures typically required for ATRP. Moreover, surface-initiated ATRP is capable of generating relatively thick films, ${ }^{[9]}$ patterned polymers, ${ }^{[10,11]}$ and block copolymers. ${ }^{[12]}$ Surface-initiated ATRP has been successfully used for biosensors and biomaterials, ${ }^{[13-22]}$ stabilization of colloidal particles, ${ }^{[23-25]}$ bioseparation, ${ }^{[26-32]}$ and nano-/microfabrication. ${ }^{[33-40]}$ Nevertheless, surface-initiated ATRP has also some profound limitations. For instance, ATRP requires initial chemical modification to introduce initiator groups to introduce initiator groups to the substrate surface. Because appropriate surface immobilization protocols are often cumbersome and far from routine use, surface-initiated ATRP is limited to a relatively small group of surfaces, such as silicon, ${ }^{[20,41]}$ glass, ${ }^{[21,42]}$ PDMS, ${ }^{[43]}$ gold,${ }^{[9,15,41]}$ and certain metal oxides. ${ }^{[19]}$ Wider application to surfaces beyond these substrates, includ- 
ing a broad range of inorganic and organic materials, will require generally applicable surface protocols.

Over the past few years, we ${ }^{[44,45]}$ and others ${ }^{[46-52]}$ exploited the use of chemical vapor deposition (CVD) polymerization to develop surface modification protocols for a wide range of different substrate materials. ${ }^{[53,54]}$ The CVD polymerization process shows promising features, like conformance to substrate topology, pinhole-free coverage even in very thin films, and the ability to penetrate ${ }^{[55]}$ and coat complex geometries. ${ }^{[56]}$ CVD polymerization often does not require solvents, plasticizers, catalysts, or accelerants minimizing cytotoxic effects by excluding potential leaching of low-molecular weight additives. ${ }^{[57,58]}$ Reactive coatings establish interfaces equipped with chemically reactive groups that can be selected from a variety of different chemical species, including amines, alcohols, aldehydes, activated carboxylic acids, alkynes, and anhydrides, ${ }^{[25,28]}$ which can be selected depending on the specific needs of a given application.

Herein we use chemical vapor deposition polymerization to create a polymeric initiator coating for surface-initiated ATRP that can be applied to a wide range of different substrate materials. As such, it effectively decouples ATRP from the need for continuously developing specialized and often expensive modification protocols. We further demonstrate the versatility of the vapor-based initiator coatings by creating non-fouling surfaces that inhibit protein adsorption and cell adhesion.

\section{Results and Discussion}

\subsection{CVD Polymerization to Prepare the Vapor-Based Initiator Coating 2}

Prior to CVD polymerization, synthesis of the starting material [2.2]paracyclophane-4-methyl 2-bromoisobutyrate (1) was established. Starting from the commercially available [2.2]paracyclophane (3), Rieche formylation with $a, a$-dichloromethyl methyl ether under the influence of titanium chloride and subsequent reduction with lithium aluminum hydride resulted in 4-hydroxymethyl[2.2]paracyclophane (5) with $71 \%$ yields (Scheme 1). Compound $\mathbf{5}$ was converted into paracyclophane (1) by reaction with 2-bromoisobutyryl bromide under
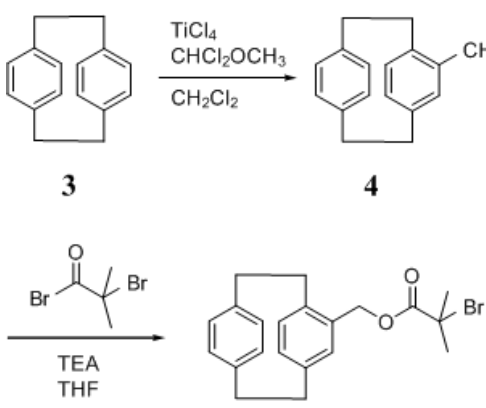

1

Scheme 1. Synthetic route towards [2.2]paracyclophane-4-methyl 2-bromoisobutyrate (1). basic conditions. After careful purification, paracyclophane $\mathbf{1}$ was isolated and used as starting material for CVD polymerization. The overall yield of the three-step synthesis was $61 \%$.

Optimized CVD polymerization conditions included sublimation of paracyclophane $\mathbf{1}(100 \mathrm{mg}, 0.26 \mathrm{mmol})$ at 115 $125^{\circ} \mathrm{C}$ under reduced pressure $(0.5 \mathrm{mbar})$ and subsequent transfer into the pyrolysis zone, which was maintained at $550{ }^{\circ} \mathrm{C}$. Deposition of the polymer onto the substrate occurred on a temperature-controlled sample holder at $15^{\circ} \mathrm{C}$. Substrates were either homogenously coated or microstructured using a recently developed masking technology (Fig. 1). ${ }^{[59]}$ Under these conditions, deposition rate of the polymer coating was about $1.0 \AA \mathrm{s} \mathrm{s}^{-1}$, as determined by quartz crystal microbalance. Film thickness depended on the amount of starting material 1 used during CVD polymerization and was 50-70 $\mathrm{nm}$ under the conditions stated above. After CVD polymerization, the resulting polymer $\mathbf{2}$ was stable in aqueous solutions and certain nonhalogenated organic solvents, such as ethanol, toluene and THF. To evaluate the adhesion properties of the initiator coating 2 , the scotch tape test ${ }^{[60]}$ was performed on polymer coated substrates including glass, silicon, quartz, PDMS, PMMA, polystyrene, and gold. During the scotch tape test, a polymer surface is first scratched in form of a grid pattern and then the scotch tape is pressed onto the surface. The surface is observed before and after peeling off the tape. The press-peeling cycle is repeated at least 5 time for each sample. On all substrates, the deposited polymer films did not peel off suggesting an excellent adhesion.

\subsection{Chemical Analysis of the Vapor-Based Initiator Coating}

Reactive polymer coating $\mathbf{2}$ was characterized using a combination of surface-sensitive methods, including XPS, grazing angle Fourier-transformed infrared reflection adsorption spectroscopy (IRRAS) and imaging ellipsometry. The XPS survey spectrum of polymer 2 is shown in Figure $2 \mathrm{~A}$ and revealed $\mathrm{C}_{1 \mathrm{~s}}$, $\mathrm{O}_{1 \mathrm{~s}}$, and $\mathrm{Br}_{3 \mathrm{p}}$ signals (red curve). Quantitative composition data are summarized in Table 1. A typical initiator coating consisted of 87.5 atom \% of carbon, 9.8 atom \% of oxygen, and 2.7 atom \% of bromine. Within the margins of error of XPS, these values compare well with the theoretical values of 87.5 atom \% for carbon, 8.3 atom \% for oxygen, and 4.2 atom $\%$ for bromine. As shown in Figure $2 \mathrm{~B}$, the high-resolution $\mathrm{C}_{1 \mathrm{~s}}$ spectrum of polymer 2 provides further insight into the chemical composition of polymer 2 . The spectrum reveals a characteristic signal at $285.0 \mathrm{eV}$, which has an intensity of 82.8 atom

Table 1. XPS analysis of poly[( $p$-xylylene-4-methyl-2-bromoisobutyrate)-co( $p$-xylylene)] before and after surface-initiated ATRP of OEGMA.

\begin{tabular}{llrrr}
\hline & & $\mathbf{C}_{\mathbf{1 s}}$ & $\mathbf{O}_{\mathbf{1 s}}$ & $\mathbf{B r}_{\mathbf{3 p}}$ \\
\hline Binding Energy [eV] & & 285.0 & 532.0 & 184.0 \\
initiator coating 2 & calcd. [\%] & 87.5 & 8.3 & 4.2 \\
& found [\%] & 87.5 & 9.8 & 2.7 \\
poly(OEGMA) modified & calcd. [\%] & 67.7 & 32.3 & - \\
& found [\%] & 69.5 & 30.5 & - \\
\hline
\end{tabular}




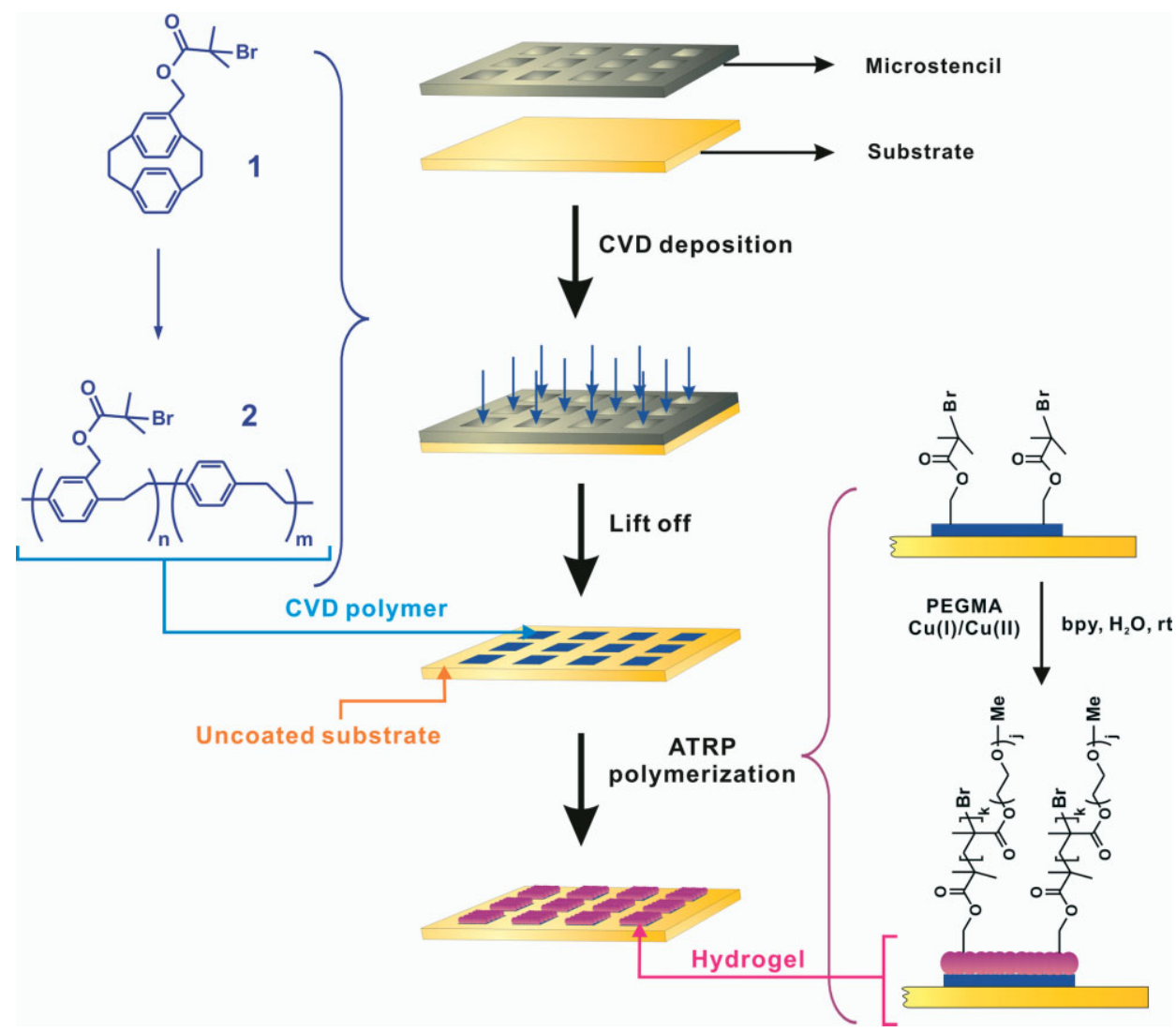

Figure 1. CVD polymerization approach to prepare the vapor-based initiator coating $\mathbf{2}$ for subsequent poly(OEGMA) modification via ATRP. A microstencil is used during CVD polymerization to direct the reactive initiator coating to defined surface areas only. Using surface-initiated ATRP, a poly(OEGMA) film is then selectively prepared at areas, where the initiator coating 2 has been deposited. The result is a microstructured hydrogel surface with potential for protein or cell patterning. ( $j, k, m, n$ denote repeating units of the corresponding structures.)

$\%$ and can be assigned to aliphatic and aromatic carbons $(\mathrm{C}-\mathrm{C}$, C-H). This signal compares well to the theoretical aliphatic and aromatic carbon concentration of 85.6 atom \%. Theoretical values were calculated based on the structure of starting material 1. Moreover, the $\mathrm{C}_{1 \mathrm{~s}}$ spectrum shows characteristic signals for ether bonds $(\mathrm{C}-\mathrm{O})$ at $286.6 \mathrm{eV}$ as well as ester bonds $(\mathrm{O}-\mathrm{C}=\mathrm{O})$ at $287.0 \mathrm{eV}$ (both 5.3 atom \%). Both signals are in good agreement with the expected theoretical values of 4.8 atom $\%$ each, as summarized in Table 1 . In addition, a characteristic signal at $289.2 \mathrm{eV}$ with 4.5 atom \% can be assigned to bromine-bound carbon ( $\underline{\mathrm{C}}-\mathrm{Br})$. This signal is in good agreement with the theoretically expected value of 4.8 atom $\%$. A smaller signal centered at $291.2 \mathrm{eV}$ can be attributed to $\pi-\pi^{*}$ shake-up signal characteristic of aromatic $\pi$ electrons and has been previously reported for similar poly ( $p$-xylylenes). ${ }^{[53]}$

The correct structure of CVD coating 2 was further confirmed by IRRAS. Figure 3a shows the FT-IR spectrum of reactive polymer coating $\mathbf{2}$ on a gold-coated silicon substrate. Characteristic functional groups of polymer $\mathbf{2}$ can be associated with absorption bands at 3004,2934 , and $2860 \mathrm{~cm}^{-1}$ due to $\mathrm{C}-\mathrm{H}$ symmetric and asymmetric stretching bands, a strong, sharp band at $1730 \mathrm{~cm}^{-1}$ indicative of the $\mathrm{C}=\mathrm{O}$ bond of the ester group, and a strong band at $1160 \mathrm{~cm}^{-1}$, which is due to $\mathrm{C}-\mathrm{O}-\mathrm{C}$ stretches of the ester group.

\subsection{Surface-Initiated ATRP from the Vapor-Based Initiator Coating}

After confirming the successful synthesis of poly[( $p$-xylylene-4-methyl-2-bromoisobutyrate)-co-( $p$-xylylene)], we conducted a series of experiments to assess the ability of these coatings to initiate ATRP. Gold substrates modified with the initiator coating 2 were incubated under inert conditions with aqueous solution of oligo(ethylene glycol) methyl ether methacrylate (OEGMA, average $M_{\mathrm{n}} c a$. 475), which contained $\mathrm{CuBr} / \mathrm{CuBr}_{2} /$ bpy as the catalyst. After ATRP, the polymer thickness of the poly(OEGMA) layer was $\sim 15 \mathrm{~nm}$, as determined by multiwavelength ellipsometry. Figure 3 shows the FTIR spectra of the initiator coating $\mathbf{2}$ before (Fig. 3a) and after ATRP (Fig. 3b). After ATRP, the strong absorption bands at 2874 and $2930 \mathrm{~cm}^{-1}$ due to $\mathrm{C}-\mathrm{H}$ stretching, a sharp band at $1732 \mathrm{~cm}^{-1}$ from $\mathrm{C}=\mathrm{O}$ stretch in the ester group, and a strong band at $1156 \mathrm{~cm}^{-1}$ due to $\mathrm{C}-\mathrm{O}-\mathrm{C}$ stretch can be clearly resolved and indicate the presence of poly(OEGMA).

To further support these data, we analyzed ATRP-modified surfaces by XPS and compared the data to the bare initiator coating 2. Figure 2A (black curve) displays XPS survey spectrum of a substrate after surface-initiated ATRP. As summarized in Table 1, chemical composition of 69.5 atom \% carbon 

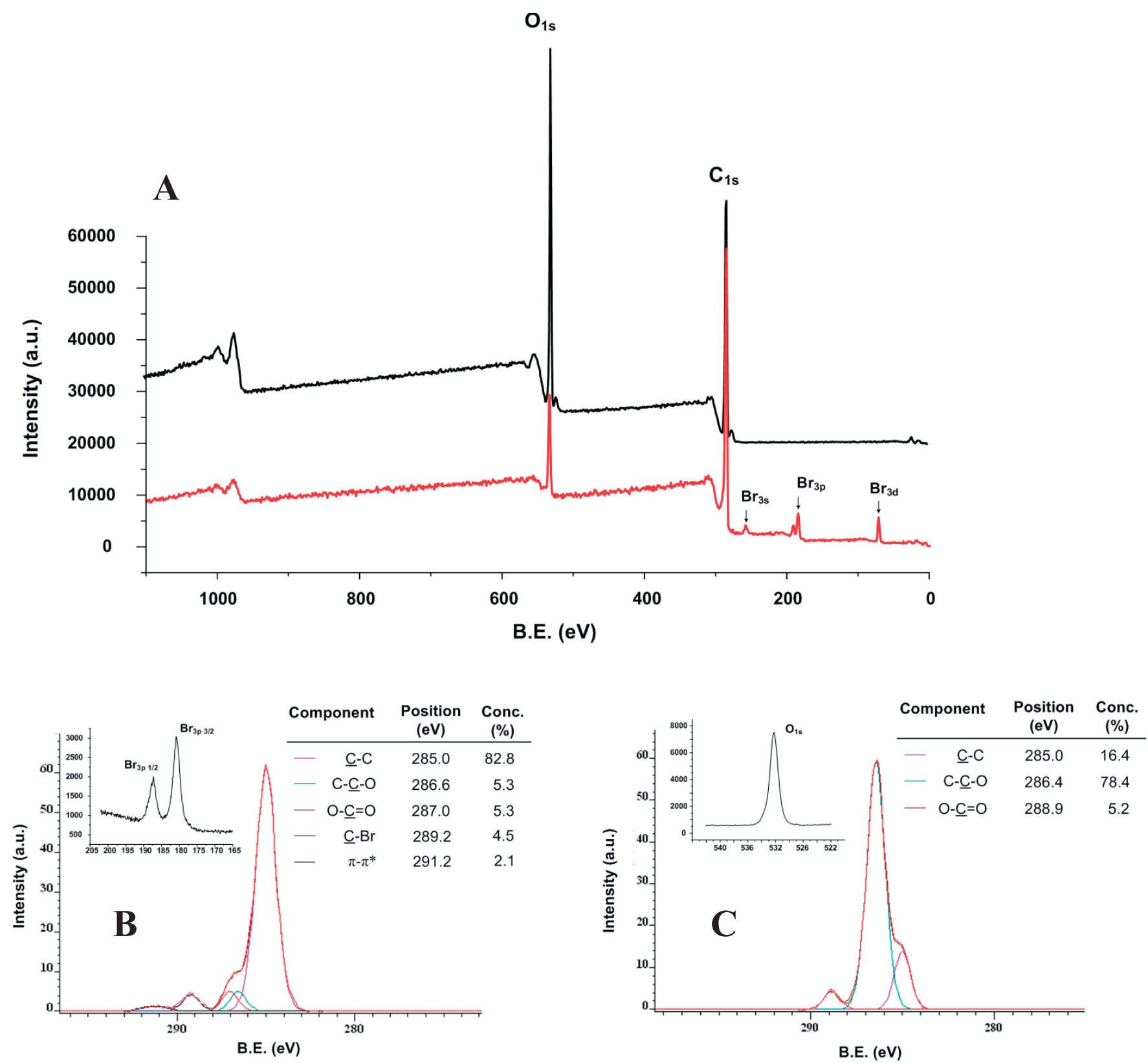

Figure 2. XPS analysis of a poly[( $p$-xylylene-4-methyl-2-bromoisobutyrate)-co-( $p$-xylylene)] film with a thickness of $25 \mathrm{~nm}$ as well as a $15 \mathrm{~nm}$-thick poly(OEGMA) film grafted onto the initiator coating 2 via ATRP. A) Survey spectra of poly[( $p$-xylylene-4-methyl-2-bromoisobutyrate)-co-( $p$-xylylene)] before (black line) and after (red line) ATRP reaction. B) High-resolution XPS spectra of carbon and bromine recorded for coating 2 . C) High-resolution XPS spectra of carbon and oxygen after ATRP of OEGMA from initiator coating 2.

and 30.5 atom \% oxygen was observed. These data correspond well with the theoretical composition of a poly(OEGMA) film with carbon and oxygen compositions of 67.7 atom $\%$ and 32.3 atom \%, respectively. Accordingly, the oxygen/carbon ratio increased from 0.11 for coating 2 to 0.48 after ATRP polymerization, which compares well with the theoretically expected ratio of 0.44 . The presence of bromine was no longer detected. Furthermore, high-resolution XPS spectral analysis of carbon is shown in Figure $2 \mathrm{C}$ and confirmed the presence of poly(OEGMA) as indicated by aliphatic $(\underline{\mathrm{C}}-\mathrm{C}, \underline{\mathrm{C}}-\mathrm{H})$, ether- bound $(\underline{\mathrm{C}}-\mathrm{O})$, and ester-bound $(\mathrm{O}-\mathrm{C}=\mathrm{O})$ carbon atoms corresponding to binding energies at 285.0, 286.4, and $288.9 \mathrm{eV}$, respectively. The aliphatic $(\underline{\mathrm{C}}-\mathrm{C}, \underline{\mathrm{C}}-\mathrm{H})$ component of 13.6 atom $\%$ compared well with the theoretical value of 16.4 atom $\%$. A significant ether (C-O) component was detected (78.4 atom $\%)$, which compared well with the theoretical value of 81.8 atom \%. In addition, characteristic ester $(\mathrm{O}-\mathrm{C}=\mathrm{O})$ atoms were detected at 5.2 atom \%, which compares to a theoretical value of 4.6 atom \%. 


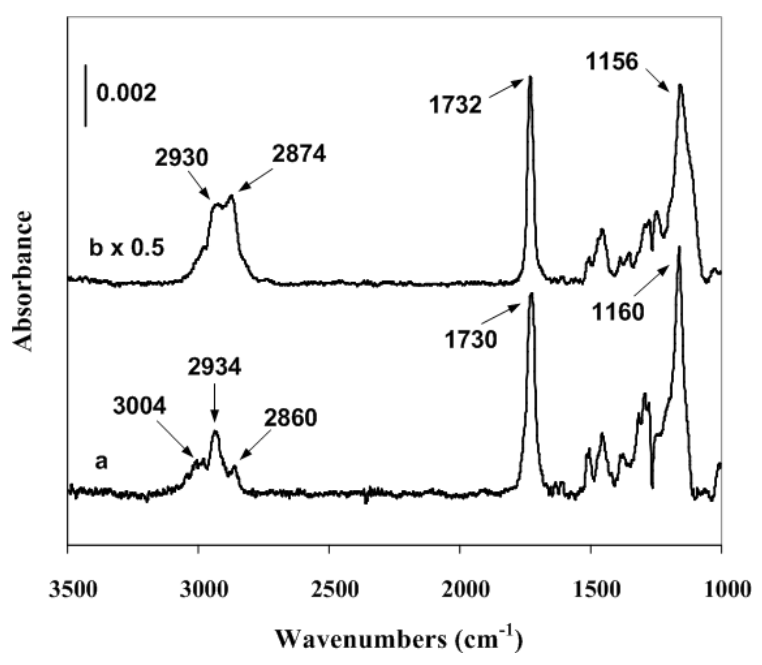

Figure 3. IRRAS spectra of poly[( $p$-xylylene-4-methyl-2-bromoisobutyrate)$c o-(p$-xylylene)] (a) deposited as a film with a thickness of $25 \mathrm{~nm}$, and of a $15 \mathrm{~nm}$-thick poly(OEGMA) film grafted onto the initiator coating 2 via surface-initiated ATRP (b). Spectra were recorded on the same sample before and after ATRP and spectrum (b) is reported after subtraction of spectrum (a) from the original spectrum (not shown).

\subsection{Reaction Kinetics of the Surface-Initiated ATRP of OEGMA Using the Vapor-Based Initiator Coating}

ATRP is often considered a controlled/living radical polymerization, because the irreversible termination reactions, such as radical coupling, are suppressed due to the very low free radical concentration. ${ }^{[61]}$ As such, ATRP should follow a linear relationship between film thickness and polymerization time. However, irreversible chain termination reactions and loss of catalyst activity cannot be entirely excluded in reality. Baker, Bruening, and co-workers' study of kinetics of surface-initiated ATRP of methyl methacrylate and methyl acrylate with a $\mathrm{Cu} /$ tris[2-(dimethylamino)ethyl]amine catalyst system suggested that the controllability of a given surface-initiated ATRP is directly related to the catalyst concentration. ${ }^{[62]}$ In our case, $\mathrm{CuBr} / \mathrm{CuBr}_{2} / \mathrm{bpy}$ was used as the catalyst system and the molar ratio was set to be $1 / 0.3 / 2.5$. In order to assess if considerable film thicknesses and sufficient polymerization controllability can be achieved by surface-initiated ATRP from reactive coating $\mathbf{2}$, a range of different catalyst concentrations was examined (Fig. 4). As expected, lower catalyst concentrations lead to slower polymerization rates and increased process controllability. When a catalyst concentration of $5.0 \mathrm{~mm}$ was employed, the film growth rate was relatively constant over a 26 -h period, but only a $\sim 15 \mathrm{~nm}$ thick film was generated after $26 \mathrm{~h}$. In contrast, when a catalyst concentration of $15 \mathrm{~mm}$ was used, a more than $100 \mathrm{~nm}$ thick polymer film was formed within $5 \mathrm{~h}$. Under the same conditions, up to $\sim 300 \mathrm{~nm}$ thick films were prepared, when surface-initiated ATRP was allowed to proceed for $24 \mathrm{~h}$. For a wide range of experimental conditions, surface-initiated ATRP of OEGMA from initiator coating 2 showed excellent controllability over a period of at least $5 \mathrm{~h}$ and was in agreement with previously reported surface-initiated ARTP reactions in aqueous media. ${ }^{[14]}$
Spatial homogeneity of the polymer coatings was further studied using a combination of imaging ellipsometry and scanning probe microscopy. Figure 4C shows the ellipsometric image of a $350 \times 650 \mu \mathrm{m}^{2}$ area of a polymer square that consists of a two layers: (i) a $66 \mathrm{~nm}$ thick layer of the initiator coating 2 and (ii) a $68 \mathrm{~nm}$ thick top layer of poly(OEGMA). The films were deposited on PMMA using vapor-assisted microstructuring in replica structures ${ }^{[59]}$ as described in the Experimental Section. The image indicates homogeneous deposition throughout the coated area. Moreover, the deposited film shows sharp boundaries suggesting that patterns can be prepared with spatial control. Further SPM analysis of modified and unmodified surface areas suggests a substantial smoothening effect due to the deposited polymer films (Fig. 5). In spite of the fact that the overall thickness of the polymer film was only $134 \mathrm{~nm}$, the root mean square roughness, recorded in the dry state, decreased from initially $1.44 \mathrm{~nm}$ for PMMA (Fig. 5A) to $0.64 \mathrm{~nm}$ after surface modification (Fig. 5B). All values are recorded for a $5 \times 5 \mu \mathrm{m}^{2}$ area. The significant decrease in surface roughness indicates that the surface modification not only changes the physico-chemical properties of the surface, but also have a leveling effect on surface roughness.

\subsection{Assessment of Non-Fouling Properties after Surface- Initiated ATRP}

Finally, we verified that the resulting poly(OEGMA) coatings exhibit expected biological properties, such as proteinand cell-resistance. Throughout the study, experiments were performed by comparing bare PMMA surfaces with surfaces modified via CVD polymerization in conjunction with ATRP. The entire sample surfaces consisting of a poly(OEGMA)coated background and unmodified PMMA squares were incubated with an aqueous buffer solution of fluorescence-labeled fibrinogen. Fibrinogen was used as a model protein, because it is the prototype of a large protein $\left(M_{\mathrm{w}}=340 \mathrm{kDa}\right)$ with strong tendency to adsorb to artificial substrates. ${ }^{[63]}$ As shown in Figure $6 \mathrm{~A}$ and $\mathrm{B}$, fibrinogen selectively adsorbed only to areas that corresponded to non-modified surfaces, i.e., surface areas without initiator coating $\mathbf{2}$. In contrast, areas that were modified with the reactive initiator coating 2 during CVD polymerization and, as such, were able to support surface-initiated ATRP polymerization of OEGMA, showed consistently low levels of protein adsorption relative to unmodified PMMA surfaces. Image analysis revealed high contrast between surfacemodified areas and background (insets of Fig. 6A and B) and unambiguously demonstrates the effectiveness of the CVDbased initiator coating in supporting ATRP polymerization. The ability to create surfaces that can support low levels of non-specific protein adsorption is an important feature of any biomedical coating technology that these coatings could be instrumental in preventing non-specific adsorption of proteins in several applications, such as biosensors or microfluidic devices.

To further complement the protein adsorption study, we investigated the adhesion of murine fibroblasts (NIH3T3 cells) to poly(OEGMA)-modified surfaces. The samples were coated with fibronectin prior to cell seeding. NIH3T3 cells were re- 


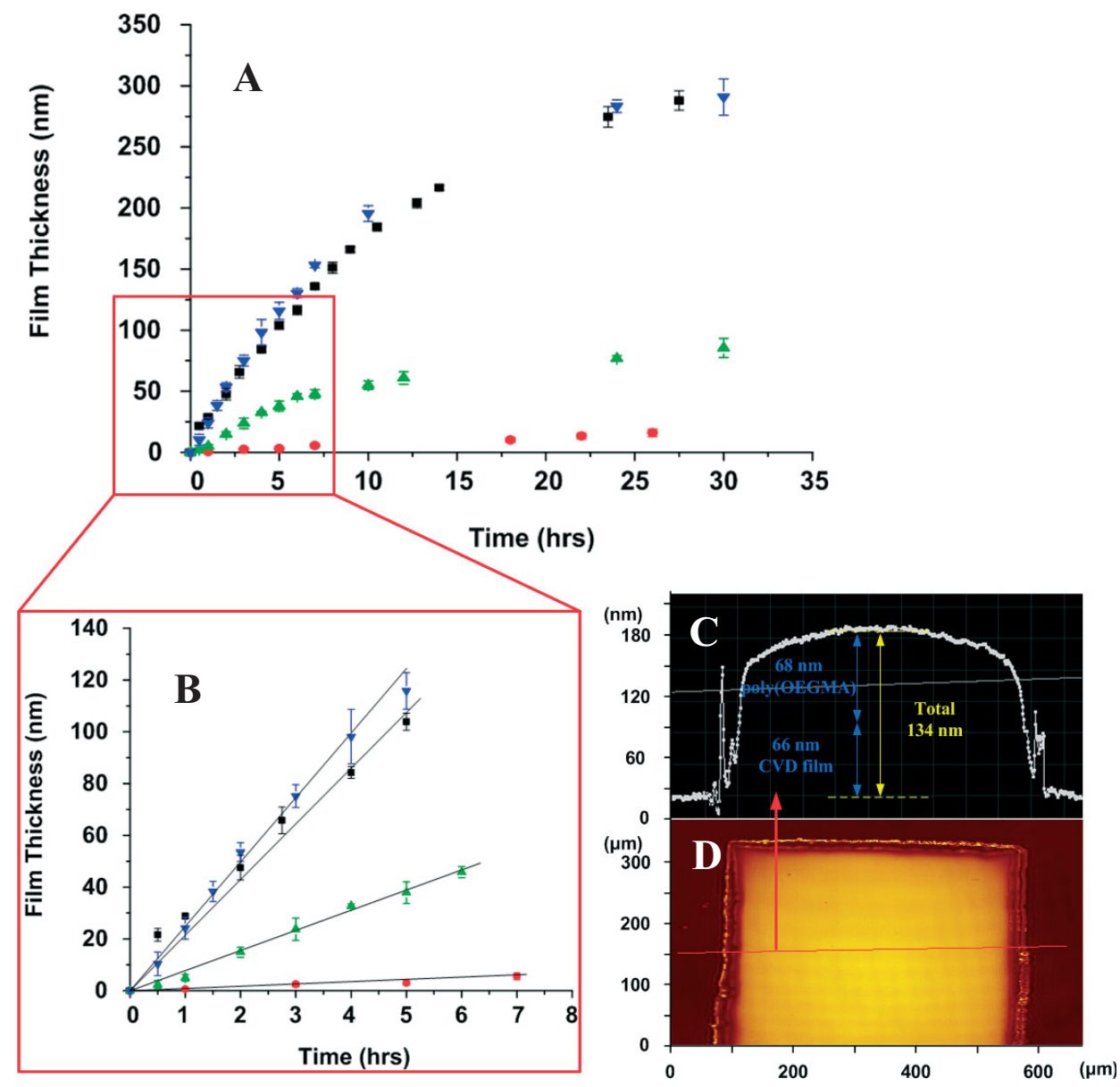

Figure 4. A) Dependence of poly(OEGMA) film thickness on polymerization time for ATRP of aqueous OEGMA (OEGMA/water, 2:1, v:v) at room temperature with different concentrations of $\mathrm{CuBr} / \mathrm{CuBr}_{2} / \mathrm{bpy}$ as catalyst system (CuBr:CuBr 2 :bpy = 1:0.3:2.5, molar ratio). ( $\left.\mathbf{\nabla}\right)$ [CuBr] $=5 \mathrm{~mm},(\boldsymbol{\Delta})$ $[\mathrm{CuBr}]=7.5 \mathrm{~mm},(\mathbf{O})[\mathrm{CuBr}]=10 \mathrm{~mm},(\mathbf{\square})[\mathrm{CuBr}]=15 \mathrm{~mm} ; n=3$. Inset $\mathrm{B}$ ) shows an enlarged view of the plot shown in $(A)$ clarifying the linear relationship between reaction time and thickness for a $5 \mathrm{~h}$ period independent of the catalyst concentration. Cross-section thickness profile (C) and thickness map (D) were acquired by using imaging ellipsometry. In this example, the thickness was found to be $66 \mathrm{~nm}$ for reactive coating 2 , and $68 \mathrm{~nm}$ for poly (OEGMA) resulting in a total thickness of $134 \mathrm{~nm}$.
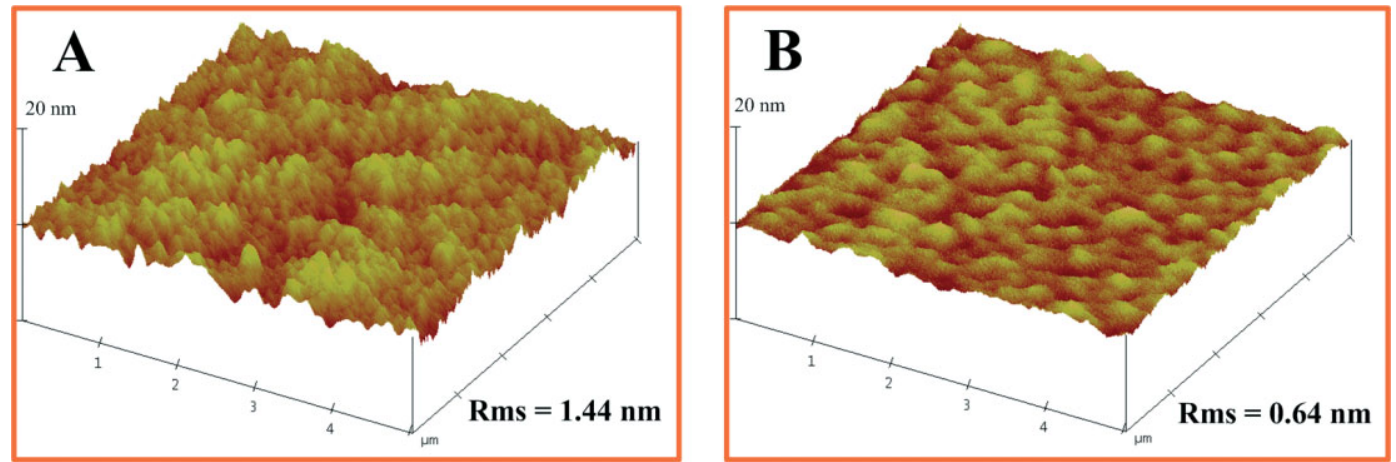

Figure 5. Surface roughness analysis by using SPM of A) PMMA background with a surface roughness of $R_{\mathrm{ms}}=1.44$ and $\mathrm{B}$ ) the same substrate after CVD deposition of coating 2 and subsequent surface-initiated ATRP $\left(R_{\mathrm{ms}}=0.64\right)$.

suspended in DMEM without FCS, and were added to wells containing the surface-modified samples. Cells were allowed to adhere onto the substrates for $2 \mathrm{~h}$ at $37^{\circ} \mathrm{C}$ in serum-free
DMEM. Samples were then evaluated via phase contrast microscopy without further washing or fixation steps. The rationale for eliminating washing steps was to ensure that the direct 

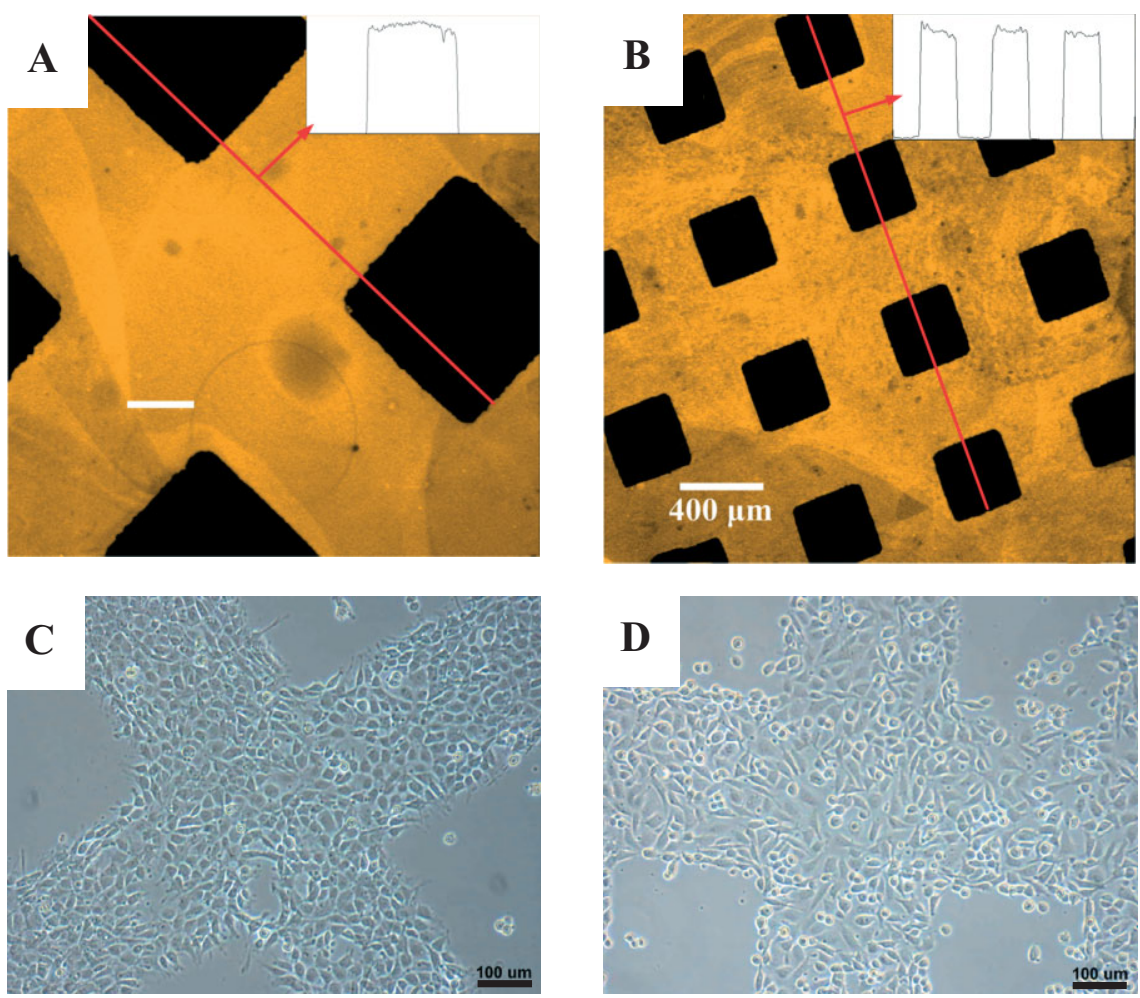

Figure 6. Biological properties of patterned surfaces. Regular (A) and large-area (B) view of a microstructured surface after exposure to an aqueous solution of fluorescence-labeled fibrinogen. The surfaces were prepared by spatially controlled deposition of the initiator coating 2 via vapor-assisted microstructuring in replica structures and subsequent ATRP. The histogram at the upper right corner of each image shows the line profile of the fluorescence intensity. C) and D): NIH3T3 cells on surface-modified PMMA substrates that were exposed to serum-free $(C)$ and serum-containing (D) media. The images have been acquired without employing any washing steps. Scale bars are $100 \mu \mathrm{m}(\mathrm{A}, \mathrm{C}, \mathrm{D})$ and $400 \mu \mathrm{m}(\mathrm{B})$, respectively. modification protocol. The method consists of CVD polymerization of a novel reactive initiator coating, poly[ $(p$-xylylene4-methyl-2-bromoisobutyrate)-co-( $p$-xylylene)] (2), which effectively supported surface-initiated ATRP. Because of the substrate independence of the CVD coating step, this approach establishes a generic surface engineering protocol that is widely applicable to a range of materials and even hybrid structures consisting of two or more materials in close proximity to each other. Moreover, the method establishes a versatile avenue to highly controlled surfaces with distinct materials features, such as the ability to support fabrication of spatially controlled bioinert surfaces for protein or cell patterning. Finally, this study manifests an important demonstration of the versatility of the CVD polymerization technology by providing a simple access route towards bioinert surfaces. In this sense, this work effectively leverages the potential of reactive coatings for biological applications by minimizing the non-specific protein adsorption and cell adhesion.

Given that the essential step, the CVD polymerization of the initiator coating $\mathbf{2}$ is equally applicable to a wide range of different substrates, we foresee the technology to be useful for the fabrication of cell-based screening devices, BioMEMS applications, and diagnostic bioassays. contact properties of these surfaces with cells were evaluated, which may be altered during subsequent washing. As shown in Figure 6C, even without further washing, a clear contrast was observed between areas that were surface modified and surfaces consisting of bare PMMA. In fact, in the areas modified via CVD polymerization and ATRP, essentially no cells were found to be adherent. After this initial $2 \mathrm{~h}$ adhesion, a subset of samples was rinsed with DMEM. The samples were then incubated with FCS-containing DMEM for additional $24 \mathrm{~h}$ and analyzed using phase contrast microscopy (Fig. 6D). Again, no washing steps were employed prior to analysis. Interestingly, even after prolonged exposure to serum-containing media, cell adhesion to poly(OEGMA)-modified surface areas was still negligible. Cell adhesion data corroborate protein adsorption data and suggest that the herein proposed method can result in remarkably protein-resistant surfaces coatings.

\section{Conclusions}

Non-fouling surface coatings have been created on a representative range of different substrates using a two-step surface

\section{Experimental}

Materials: Unless otherwise specified, all chemicals were obtained from Aldrich. [2.2]Paracyclophane (PCS), Titanium (IV) chloride (99.9\%), $a, a$-dichloromethyl methyl ether (98\%), lithium aluminium hydride (Acros, $95 \%$ ), 2-bromoisobutyryl bromide (98\%), triethylamine (TEA, $99.5 \%$ ), $\mathrm{Cu}(\mathrm{I}) \mathrm{Br}(99.999 \%), \mathrm{Cu}(\mathrm{II}) \mathrm{Br}_{2}$ (Fluka, $99 \%$ ), anhydrous THF (EMD) were used as received. $\mathrm{CH}_{2} \mathrm{Cl}_{2}$ was distilled over calcium hydride. 2,2'-dipyridyl (bpy, $99 \%$ ) was sublimed prior to use. Oligo(ethylene glycol) methyl ether methacrylate (OEGMA, average $M_{\mathrm{n}}$ : ca. 475) was passed through a $20 \mathrm{~cm}$ column of inhibitor remover and subsequently stored at $-20^{\circ} \mathrm{C}$ in the dark.

Preparation of [2.2]Paracyclophane-4-methyl 2-Bromoisobutyrate: Under nitrogen, titanium (IV) chloride $(9.0 \mathrm{~mL}, 82 \mathrm{mmol})$ was added dropwise over $20 \mathrm{~min}$ to an ice-cooled $1 \mathrm{~L}$ round bottom flask charged with anhydrous $\mathrm{CH}_{2} \mathrm{Cl}_{2}(400 \mathrm{~mL})$ and [2.2] paracyclophane $(10.0 \mathrm{~g}$, $48 \mathrm{mmol}$ ). After the addition, the mixture was stirred for $20 \mathrm{~min}$, followed by dropwise addition of a,a-dichloromethyl methyl ether $(7.0 \mathrm{~mL}, 77 \mathrm{mmol})$. The reaction mixture was stirred at $0{ }^{\circ} \mathrm{C}$ for $90 \mathrm{~min}$ and was subsequently poured into ice water $(300 \mathrm{~mL})$. The organic layer was washed with $3 \mathrm{M} \mathrm{HCl}(2 \times 300 \mathrm{~mL})$, water $(2 \times 300 \mathrm{~mL})$, and saturated aqueous sodium bicarbonate $(2 \times 300 \mathrm{~mL})$, and dried over $\mathrm{Na}_{2} \mathrm{SO}_{4}$. After filtration and removal of the solvent, the crude product was dissolved in anhydrous THF $(100 \mathrm{~mL})$. To this THF solution, LAH (3.7 g, $96 \mathrm{mmol}$ ) was carefully added and the mixture was stirred at 
room temperature for $36 \mathrm{~h}$. The excess LAH was then decomposed by careful addition of ethyl acetate. The solution was then diluted by diethyl ether $(200 \mathrm{~mL})$, washed with $3 \mathrm{M} \mathrm{HCl}(3 \times 200 \mathrm{~mL})$ and water $(2 \times 200 \mathrm{~mL})$, and dried over $\mathrm{Na}_{2} \mathrm{SO}_{4}$. The crude product was isolated and purified on silica gel using hexane/ethyl acetate (4/1) as eluent to yield 4-(hydroxymethyl)[2.2]paracyclophane as white crystals $(8.1 \mathrm{~g}$, $71 \%$ ). Next, 4-(hydroxymethyl)[2.2]paracyclophane (5.0 g, $21 \mathrm{mmol}$ ) and 2-bromoisobutyryl bromide $(5.2 \mathrm{~mL}, 42 \mathrm{mmol})$ were dissolved in anhydrous THF $(100 \mathrm{~mL})$ and cooled at $0{ }^{\circ} \mathrm{C}$ under nitrogen. To this stirred solution, TEA $(14.6 \mathrm{~mL}, 105 \mathrm{mmol})$ was added dropwise over $30 \mathrm{~min}$ and the solution was stirred for $2 \mathrm{~h}$ at $0{ }^{\circ} \mathrm{C}$. The solution was then diluted with diethyl ether $(200 \mathrm{~mL})$, washed with $3 \mathrm{M} \mathrm{HCl}$ $(3 \times 200 \mathrm{~mL})$ and water $(2 \times 200 \mathrm{~mL})$, and dried over $\mathrm{Na}_{2} \mathrm{SO}_{4}$. The isolated, crude product was purified on silica gel using hexane/ethyl acetate $(85 / 15)$ to yield [2.2]paracyclophane-4-methyl 2-bromoisobutyrate as off-white crystals $(7.0 \mathrm{~g}, 86 \%):{ }^{1} \mathrm{H}$ NMR $(\delta): 6.64(\mathrm{~m}, 1 \mathrm{H}), 6.50(\mathrm{~m}$, $4 \mathrm{H}), 6.40(\mathrm{~m}, 2 \mathrm{H}), 5.15(\mathrm{~d}, 1 \mathrm{H}), 4.96(\mathrm{~d}, 1 \mathrm{H}), 3.35(\mathrm{~m}, 1 \mathrm{H}), 3.07(\mathrm{br} \mathrm{m}$, $6 \mathrm{H}), 2.89(\mathrm{~m}, 1 \mathrm{H}), 1.94(\mathrm{~d}, 6 \mathrm{H}) ;{ }^{13} \mathrm{C}$ NMR $\delta 171.63,140.12,139.50$, 139.12, 138.06, 135.03, 133.94, 133.27, 133.15, 133.14, 132.88, 132.27, 129.40, 66.95, 55.78, 35.23, 34.97, 34.32, 32.84, 30.74, 30.72; IR: 3008 (w), $2926(\mathrm{~m}), 2852(\mathrm{~m}), 1730(\mathrm{vs}), 1269(\mathrm{~s}), 1160(\mathrm{~s}), 1104(\mathrm{~s}) ; \mathrm{MS}(\mathrm{m} / \mathrm{z}$ $(\%)): 387.2(M+1)$

Polymerization of OEGMA from Initiator Coating 2: For kinetic studies, an aqueous solution of OEGMA (OEGMA/ $\mathrm{H}_{2} \mathrm{O}, 2: 1$, v:v), $2,2^{\prime}$-bipyridine (bpy), and $\mathrm{CuBr}_{2}$ was stirred in a Schlenk flask at room temperature. The homogeneous solution was degassed using three freeze-pump-thaw cycles. Next, $\mathrm{CuBr}$ was added under nitrogen purge to the frozen solution and the molar ratio of $\mathrm{CuBr} / \mathrm{CuBr}_{2} / \mathrm{bpy}$ was set to be $1 / 0.3 / 2.5$. The mixture was warmed up to room temperature and was stirred until a homogeneous dark brown solution was formed. The solution was then transferred into a nitrogen-purged glovebag, and split into $20 \mathrm{~mL}$ scintillation vials containing one CVD-coated substrate per vial. The polymerizations proceeded at room temperature for a set reaction time. Samples were analyzed in triplicate. To prepare samples for protein adsorption and cell adhesion studies, the $\mathrm{CuBr}$ concentration was $10 \mathrm{mM}$ and polymerizations proceeded for $3 \mathrm{~h}$ at room temperature.

Fabrication of Microstencils: Micropatterns were designed using AutoCAD, and the design was printed on high-resolution emulsion transparencies (40640 DPI, Photoplot Store). For fabrication of the master, a layer of photoresist (SU-8 100, MicroChem Co.) was spincoated at $1000 \mathrm{rpm}$ for $30 \mathrm{~s}$ onto a silicon wafer. The wafer was softbaked at $65{ }^{\circ} \mathrm{C}$ for $30 \mathrm{~min}$ followed by $95{ }^{\circ} \mathrm{C}$ for $90 \mathrm{~min}$, and then exposed to UV radiation $\left(404.7 \mathrm{~nm}, 10 \mathrm{~mJ} \mathrm{~cm}^{-2}\right)$ for 4 min to define the desired microstructure from the transparency mask. Post-exposure bake was performed at $65^{\circ} \mathrm{C}$ for $1 \mathrm{~min}$ followed by $95^{\circ} \mathrm{C}$ for $20 \mathrm{~min}$. After removal of the activated photoresist by exposing to a SU-8 developer solution (MicroChem Co.) for $20 \mathrm{~min}$ with agitation, the resulting SU-8 master was cleaned with isopropyl alcohol (IPA). Uniformly mixed PDMS prepolymer and curing agent (Sylgard 184, Dow Corning) were combined at a ratio of 10:1 and were spin-coated at $1200 \mathrm{rpm}$ for $30 \mathrm{~s}$ onto the SU-8 master, and resulted in a $150 \mu \mathrm{m}$ thick layer. The PDMS prepolymer was cured at $70^{\circ} \mathrm{C}$ for $1 \mathrm{~h}$. Finally, a microstencil with embossed microgeometries was released from the SU-8 master. The fabricated PDMS microstencils were $150 \mu \mathrm{m}$ high, and had squareshaped columns of $500 \mu \mathrm{m} \times 500 \mu \mathrm{m}$. The replicated PDMS microstencil was brought into intimate contact with the substrate and the sample was placed onto the sample holder located in the deposition chamber for further modification by CVD polymerization.

CVD Polymerization: Poly[( $p$-xylylene-4-methyl-2-bromoisobutyrate)-co-( $p$-xylylene)] (2) was prepared via CVD polymerization in a custom-made CVD polymerization system[44]. The starting material, [2.2]paracyclophane-4-methyl 2-bromoisobutyrate (1), was sublimed under vacuum and converted by pyrolysis into the corresponding quinodimethanes, which spontaneously polymerized upon condensation to the cooled substrate surface, which was maintained at $15^{\circ} \mathrm{C}$. Throughout CVD polymerization, a constant argon flow of $20 \mathrm{sccm}$ and a working pressure of $0.5 \mathrm{mbar}$ were maintained. The pyrolysis temperature was set to be $550^{\circ} \mathrm{C}$ and sublimation temperatures were between 115 $125^{\circ} \mathrm{C}$ under these conditions. CVD Polymerization spontaneously oc- curred on samples placed on a rotating, cooled sample holder. In cases, where patterned substrates were required, the PDMS microstencils were sealed to the substrates during CVD polymerization.

Surface Analysis: X-ray photoelectron spectroscopy (XPS) data were recorded on an Axis Ultra X-ray photoelectron spectrometer (Kratos Analyticals, UK) equipped with a monochromatized $\mathrm{Al} \mathrm{K \alpha} \mathrm{X}$-ray source. XPS spectra were recorded with an X-ray power of $150 \mathrm{~kW}$. Pass energies were $160.0 \mathrm{eV}$ and $20.0 \mathrm{eV}$ for survey spectra and highresolution elemental spectra, respectively. XPS atomic analysis was reported based on atomic concentrations (\%); theoretical values were calculated on the basis of structure 1. Surface morphology data were obtained with a Nanoscope IIIa scanning probe microscopy (Digital Instruments/Veeco, USA) using a JV type scanner $(150 \mu \mathrm{m} \times 150 \mu \mathrm{m}$ maximum scan size). NSC 16 cantilevers (MikroMasch, USA) with spring constants between $25 \mathrm{~N} / \mathrm{m}$ and $60 \mathrm{~N} / \mathrm{m}$, and resonance frequencies of $150-170 \mathrm{kHz}$ were used as AFM tips. Scanning size for the images shown herein was $5 \mu \mathrm{m} \times 5 \mu \mathrm{m}$ at a scan rate of $0.8 \mathrm{~Hz}$. Film thicknesses were measured using a multi-wavelength rotating analyzer ellipsometer (M-44, J. A. Woollam) at an incident angle of $75^{\circ}$. The data were analyzed using WVASE32 software, and thickness determinations were performed on at least three spots that were at least $3 \mathrm{~mm}$ away from each other. Thickness measurements were recorded by fitting the ellipsometric psi and delta data with fixed An (1.46) and Bn (0.01) values using a Cauchy model and software module integrated with the system. For thickness imaging, data were recorded at an angle of incident of $65^{\circ}$ using an $\mathrm{EP}^{3}$-SW imaging ellipsometer (Nanofilm Technologie $\mathrm{GmbH}$, Germany) equipped with a $532 \mathrm{~nm}$ solid state laser operated at $15 \mathrm{~mW}$. Measurements were performed by an imaging scanner with a lateral resolution of $1 \mu \mathrm{m}$ at a field of view of about $100 \mu \mathrm{m} \times 500 \mu \mathrm{m}$. The images were captured using a CCD camera with a maximum resolution of $768 \times 572$ pixels. Infrared spectroscopy was performed using a Thermo/Nicolet 6700 spectrometer utilizing the grazing angle accessory (Smart SAGA) at a grazing angle of $85^{\circ}$.

Protein Adsorption Studies: Alexa Fluor 546-conjugated fibrinogen (Molecular Probes Inc.) was used as model protein to study the fouling property of surface-modified substrates. Protein solutions were prepared at a concentration of $60 \mu \mathrm{g} \mathrm{ml}^{-1}$ according to manufacturer's manual. Samples were incubated with the protein solution for $10 \mathrm{~min}$. After incubation, phosphate buffered saline (PBS) and DI-water were used to rinse off excess adsorbed proteins. The resulting samples were then examined by fluorescence microscopy (TE 200, Nikon).

Cell Adhesion Studies: Cryopreserved murine fibroblasts (NIH3T3) were purchased from ATCC (Manassas, VA) and cultured in DMEM containing $10 \%$ fetal calf serum (FCS). For cell adhesion, PMMA was used as the substrate. ATRP/poly(OEGMA) modified surfaces were rinsed in $\mathrm{EtOH}$, dried, and coated with $25 \mathrm{mg} \mathrm{ml}^{-1}$ fibronectin for $20 \mathrm{~min}$ at $37^{\circ} \mathrm{C}$. These surfaces were then rinsed with PBS, and briefly maintained in Dulbecco's Modified Eagle Medium (DMEM) (ATCC, Manassas, VA) without FCS (Invitrogen, Carlsbad, CA) until cells were ready to be seeded. Cells were re-suspended in DMEM without FCS, and added to the wells containing the modified surfaces. They were then allowed to adhere onto the substrates for $2 \mathrm{~h}$ at $37^{\circ} \mathrm{C}$ in DMEM without serum, and analyzed by phase contrast microscopy. Alternatively, a sub-group of samples was rinsed with DMEM after this initial $2 \mathrm{~h}$ adhesion, and the media was exchanged to FCS-containing DMEM. The substrates were then incubated for additional $24 \mathrm{~h}$ and analyzed by phase contrast microscopy without washing.

Received: July 18, 2007 Revised: September 21, 2007 Published online: December 18, 2007

[1] J. D. Tian, H. Gong, N. J. Sheng, X. C. Zhou, E. Gulari, X. L. Gao, G. Church, Nature 2004, 432, 1050.

[2] J. P. Pellois, X. C. Zhou, O. Srivannavit, T. C. Zhou, E. Gulari, X. L. Gao, Nat. Biotechnol. 2002, 20, 922.

[3] A. Berg, W. Olthius, P. Bergveld, Micro Total Analysis Systems, Kluwer, Dordrecht, The Netherlands 2000. 
[4] A. Y. Fu, C. Spence, A. Scherer, F. H. Arnold, S. R. Quake, Nat. Biotechnol. 1999, 17, 1109.

[5] C. S. Chen, M. Mrksich, S. Huang, G. M. Whitesides, D. E. Ingber, Science 1997, 276, 1425.

[6] E. M. Lucchetta, J. H. Lee, L. A. Fu, N. H. Patel, R. F. Ismagilov, Nature 2005, 434, 1134

[7] Y. Li, T. Pfohl, J. H. Kim, M. Yasa, Z. Wen, M. W. Kim, C. R. Safina, Biomed. Microdevices 2001, 3, 239.

[8] Y. Tsujii, K. Ohno, S. Yamamoto, A. Goto, T. Fukuda, in Surface-Initiated Polymerization I, Vol. 197 (Ed: R. Jordan), Springer New York 2006, 1.

[9] Z. Bao, M. L. Bruening, G. L. Baker, J. Am. Chem. Soc. 2006, 128, 9056.

[10] Y. Liu, V. Klep, I. Luzinov, J. Am. Chem. Soc. 2006, 128, 8106.

[11] F. Zhou, Z. Zheng, B. Yu, W. Liu, W. T. S. Huck, J. Am. Chem. Soc 2006, $128,16253$.

[12] J. Di, D. Y. Sogah, Macromolecules 2006, 39, 5052.

[13] W. K. Cho, B. Kong, I. S. Choi, Langmuir 2007, 23, 5678.

[14] H. Ma, M. Wells, T. P. Beebe, Jr., A. Chilkoti, Adv. Funct. Mater. 2006, 16,640 .

[15] B. S. Lee, J. K. Lee, W.-J. Kim, Y. H. Jung, S. J. Sim, J. Lee, I. S. Choi, Biomacromolecules 2007, 8, 744.

[16] C. Gao, S. Muthukrishnan, W. Li, J. Yuan, Y. Xu, A. H. E. Mueller, Macromolecules 2007, 40, 1803.

[17] F. Hu, K. G. Neoh, L. Cen, E.-T. Kang, Biomacromolecules 2006, 7, 809.

[18] J. Y. Huang, H. Murata, R. R. Koepsel, A. J. Russell, K. Matyjaszewski, Biomacromolecules 2007, 8, 1396.

[19] X. Fan, L. Lin, J. L. Dalsin, P. B. Messersmith, J. Am. Chem. Soc $\mathbf{2 0 0 5}, 127,15843$

[20] I. Cringus-Fundeanu, J. Luijten, H. C. Van der Mei, H. J. Busscher, A. J. Schouten, Langmuir 2007, 23, 5120.

[21] Z. Zhang, T. Chao, S. Chen, S. Jiang, Langmuir 2006, 22, 10072.

[22] M. Ignatova, S. Voccia, B. Gilbert, N. Markova, D. Cossement, R. Gouttebaron, R. Jerome, C. Jerome, Langmuir 2006, 22, 255.

[23] T. Liu, R. Casado-Portilla, J. Belmont, K. Matyjaszewski, J. Polym. Sci. Part A 2005, 43, 4695 .

[24] T. Liu, S. Jia, T. Kowalewski, K. Matyjaszewski, R. Casado-Portilla, J. Belmont, Macromolecules 2006, 39, 548.

[25] H. W. Duan, M. Kuang, D. Y. Wang, D. G. Kurth, H. Mohwald, Angew. Chem. Int. Ed. 2005, 44, 1717.

[26] L. Sun, J. H. Dai, G. L. Baker, M. L. Bruening, Chem. Mater. 2006 18,4033

[27] I. Lokuge, X. Wang, P. W. Bohn, Langmuir 2007, 23, 305.

[28] A. Kusumo, L. Bombalski, Q. Lin, K. Matyjaszewski, J. W. Schneider, R. D. Tilton, Langmuir 2007, 23, 4448.

[29] L. Sun, G. L. Baker, M. L. Bruening, Macromolecules 2005, 38, 2307.

[30] H.-J. Wang, W.-H. Zhou, X.-F. Yin, Z.-X. Zhuang, H.-H. Yang, X.-R. Wang, J. Am. Chem. Soc. 2006, 128, 15954.

[31] E. Unsal, B. Elmas, B. Caglayan, M. Tuncel, S. Patir, A. Tuncel, Anal Chem. 2006, 78, 5868 .
[32] N. Idota, A. Kikuchi, J. Kobayashi, Y. Akiyama, K. Sakai, T. Okano, Langmuir 2006, 22, 425 .

[33] D. Li, Q. He, Y. Cui, K. Wang, X. Zhang, J. Li, Chem. Eur. J. 2007, 13 , 2224.

[34] L. Li, C. M. Lukehart, Chem. Mater. 2006, 18, 94.

[35] M. Lattuada, T. A. Hatton, Langmuir 2007, 23, 2158.

[36] M. J. Mulvihill, B. L. Rupert, R. He, A. Hochbaum, J. Arnold, P. Yang, J. Am. Chem. Soc. 2005, 127, 16040.

[37] H. Zhao, X. Kang, L. Liu, Macromolecules 2005, 38, 10619.

[38] D. Li, G. L. Jones, J. R. Dunlap, F. Hua, B. Zhao, Langmuir 2006, 22 3344.

[39] T. Morinaga, M. Ohkura, K. Ohno, Y. Tsujii, T. Fukuda, Macromolecules 2007, 40, 1159

[40] B. L. Rupert, M. J. Mulvihill, J. Arnold, Chem. Mater. 2006, 18, 5045.

[41] Z. Bao, M. L. Bruening, G. L. Baker, Macromolecules 2006, 39, 5251.

[42] H. Ma, D. Li, X. Sheng, B. Zhao, A. Chilkoti, Langmuir 2006, 22, 3751.

[43] D. Q. Xiao, H. Zhang, M. Wirth, Langmuir 2002, 18, 9971.

[44] J. Lahann, Polym. Int. 2006, 55, 1361.

[45] J. Lahann, Chem. Eng. Commun. 2006, 193, 1457.

[46] T. P. Martin, S. E. Kooi, S. H. Chang, K. L. Sedransk, K. K. Gleason, Biomaterials 2007, 28, 909.

[47] S. J. Limb, C. B. Labelle, K. K. Gleason, D. J. Edell, E. F. Gleason, Appl. Phys. Lett. 1996, 68, 2810.

[48] H. W. Gu, C. J. Xu, L. T. Weng, B. Xu, J. Am. Chem. Soc. 2003, 125, 9256.

[49] P. Hanefeld, U. Westedt, R. Wombacher, T. Kissel, A. Schaper, J. H Wendorff, A. Greiner, Biomacromolecules 2006, 7, 2086.

[50] N. H. Lee, C. W. Frank, Langmuir 2003, 19, 1295.

[51] Y. C. Chang, C. W. Frank, Langmuir 1998, 14, 326.

[52] J. J. Senkevich, S. B. Desu, Thin Solid Films 1998, 322, 148

[53] J. Lahann, R. Langer, Macromolecules 2002, 35, 4380.

[54] J. Lahann, I. S. Choi, J. Lee, K. F. Jenson, R. Langer, Angew. Chem. Int. Ed. 2001, 40, 3166.

[55] H. Y. Chen, Y. Elkasabi, J. Lahann, J. Am. Chem. Soc. 2006, 128, 374.

[56] J. Lahann, D. Klee, H. Hocker, Macromol. Rapid Commun. 1998, 19 , 441.

[57] J. Lahann, D. Klee, W. Pluester, H. Hoecker, Biomaterials 2001, 22 , 817.

[58] K. Schurmann, J. Lahann, P. Niggemann, B. Klosterhalfen, J. Meyer, A. Kulisch, D. Klee, R. W. Gunther, D. Vorwerk, Radiology 2004, 230 151.

[59] H. Y. Chen, J. Lahann, Adv. Mater. 2007, 19, 3801.

[60] H. Nandivada, H. Y. Chen, J. Lahann, Macromol. Rapid Commun. 2005, 26, 1794.

[61] K. Matyjaszewski, J. H. Xia, Chem. Rev. 2001, 101, 2921.

[62] J. B. Kim, W. X. Huang, M. D. Miller, G. L. Baker, M. L. Bruening, J. Polym. Sci. Part A 2003, 41, 386.

[63] B. D. Ratner, Biomaterials Science: An Introduction to Materials in Medicine, Elsevier, Amsterdam 2004 